\title{
Note on Some Abnormalities of Labial Palps and Foot of Mytilus edulis.
}

$\mathrm{By}$

\author{
D. Atkins, B.Sc.
}

With 7 Figures in the Text.

In view of Pelseneer's work on "Les Variations et leur Hérédité chez les Mollusques,"* it seems worth while to record briefly certain observed abnormalities of the labial palps and the foot of Mytilus edulis. Among some thousands of specimens examined, however, such conditions were rare, and it is probable that at least some of them arose through injury.

\section{Labial Palps.}

The abnormality of the palps most generally met with is evidently the result of natural regeneration, following injury to the tips of the palps. From the injured surface tiny outgrowths arise, usually three in number, two of which appear to have a common base. Figures 1, A-C, shew different degrees of regeneration; two examples have been seen in approximately similar conditions. (The normal tip of the palp may be seen at $\mathrm{P}$ in Figure 2.)

Pelseneer (p. 181) records the finding by Sykes of a specimen of Tellina incarnata in which the palps were missing, but gives no further examples of variation in palps. However, his Figure 121 (p. 204) of a gill of Boreochiton marginatus with trifurcated tip shows a similar state of affairs to that recorded in this note for the palps of $M$. edulis.

Bifurcation of the tip of the palp has been observed in one or two instances.

The right inner palp of a Mytilus from Padstow showed two small accessory palps near the base (Figure 2) ; these had a common base, only the tips, which pointed in opposite directions, being free. In preservation the tips have become curled, and that of the more proximal secondary palp is hidden beneath that of the more distal one. A second example of this type of accessory palps was noted on the right inner palp of another Mytilus from the same locality, but in this instance they originated about

* P. Pelseneer, Les Variations et leur Hérédité chez les Mollusques. Acad. Roy. Bel. Mém., 2nd sér., Tome V, 1920. 

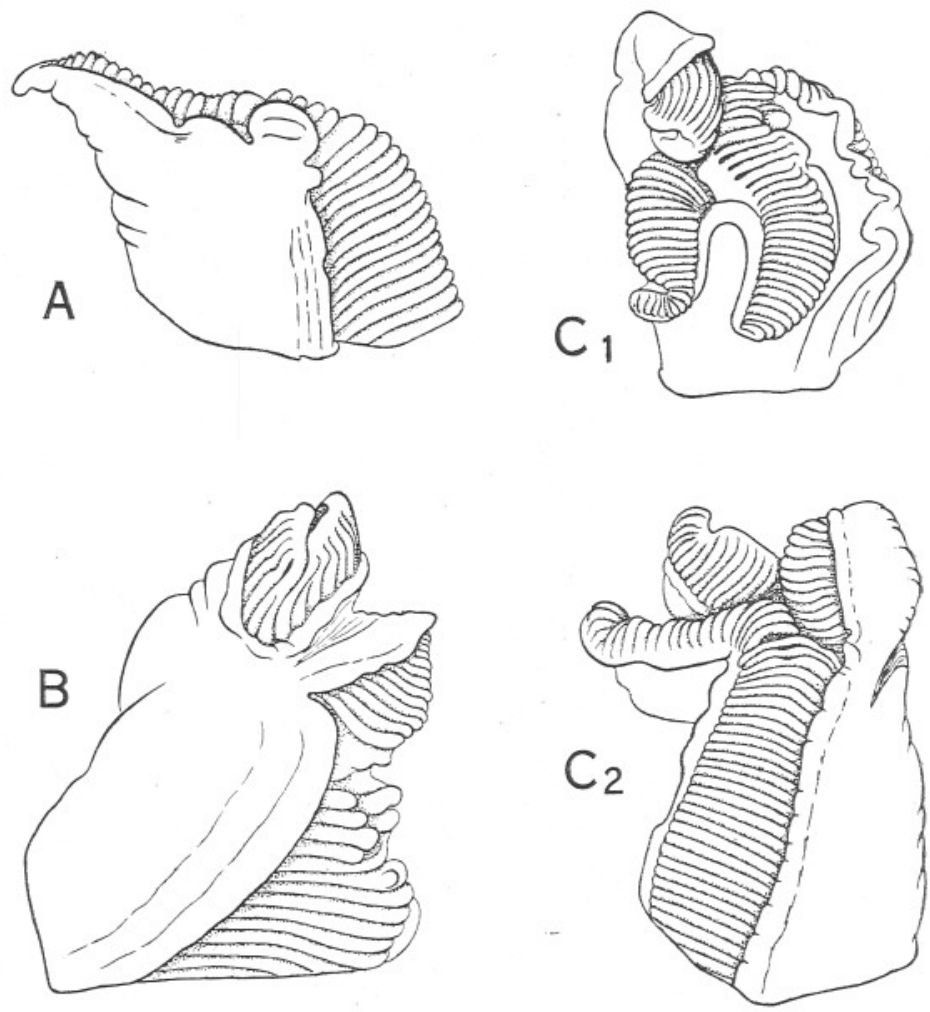

FIG. 1, A-c.-Mytilus edulis. Sketches showing stages in the formation of outgrowths from the tips of three palps, A, being the youngest and $\mathrm{C}$, the oldest stage. In Cl, the trifurcated tip of the palp has become folded back on to the smooth outer surface during fixation; in $\mathrm{C} 2$, it has been forcibly flattened out. $\times$ ca. $6 \frac{1}{4}$.

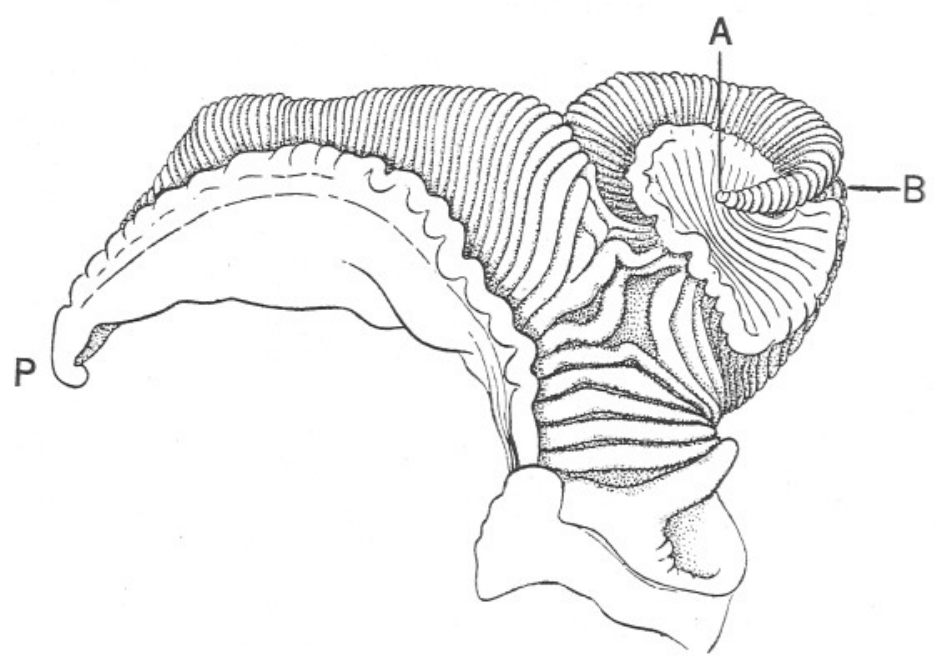

FIG. 2.-M. edulis. Sketch of palp with two accessory palps near the base. These have a common base, the tips only being free; that of the more proximal one, B, is hidden beneath the other, A. P, tip of principal palp. $\times$ ca. $6 \frac{1}{4}$. 


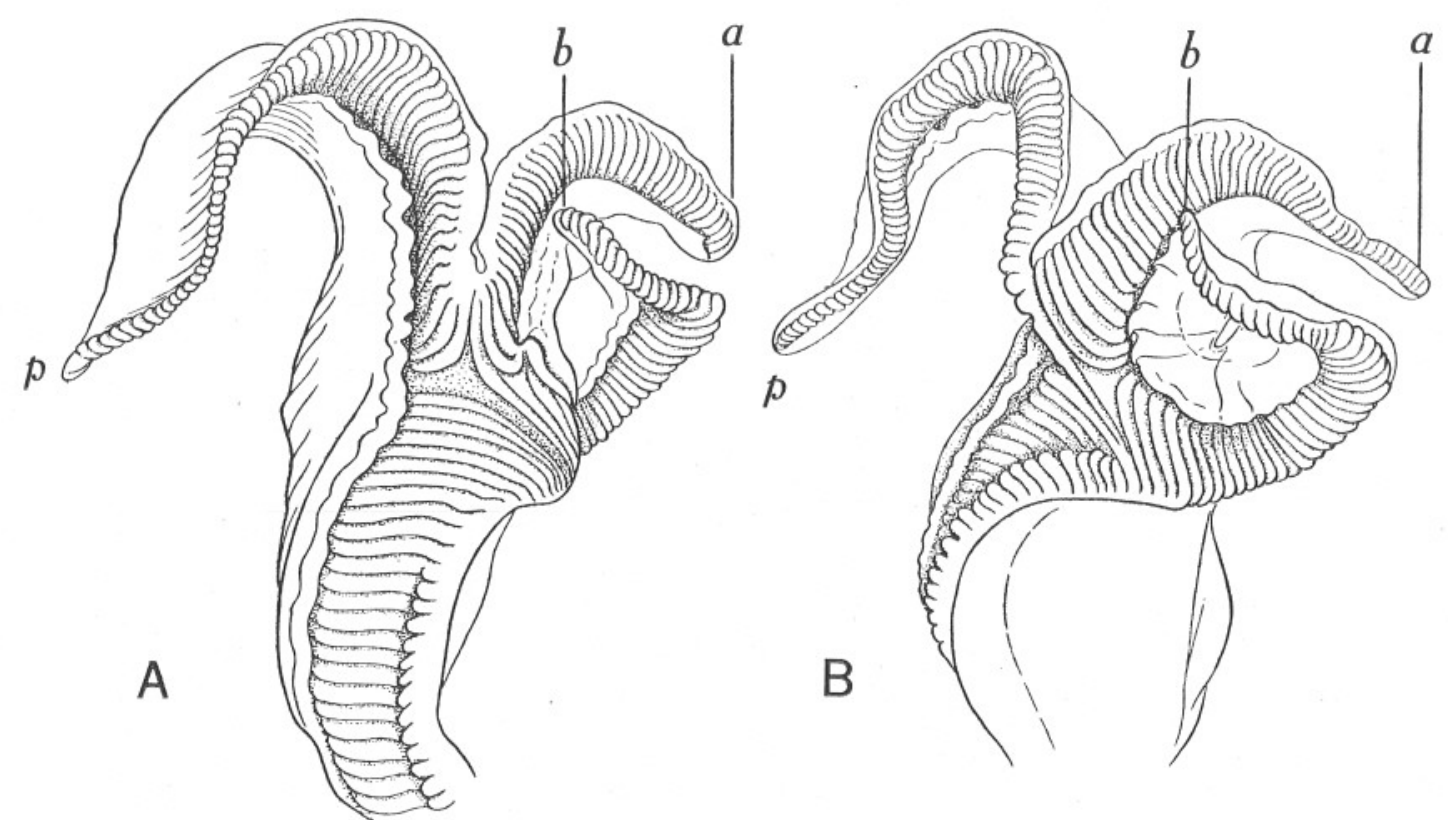

Fig. 3.-M. edulis. Different views (A and B) of two accessory palps, $a$ and $b$, originating from about midway along the length of the principal palp. $p$, tip of principal palp. $\times$ ca. $6 \frac{1}{4}$. 
midway along the length of the principal palp, and were more highly developed (Figure 3).

A tiny accessory palp originating from near the base of a left inner palp,

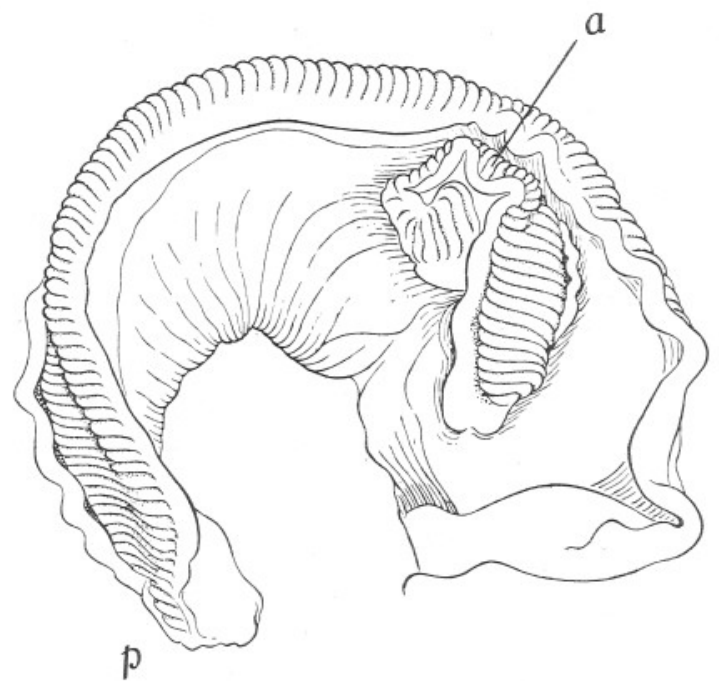

FIG. 4.-M.edulis. Palp with a small accessory palp, $a$, near the base on the smooth outer surface. $p$, tip of principal palp. $\times$ ca. $6 \frac{1}{4}$.

on its smooth outer surface, is shown in Figure 4. In this instance the difference in size of the principal and secondary palp is marked.

Foot.

Several different types of foot abnormality have been noted in $M$. edulis. That most generally met with was a small foot-like outgrowth, or rudimentary accessory foot, originating from near the base of the primary foot, the latter showing no injury to its tip. The outgrowth was lateral, but somewhat dorsal in position (see Figure 5), and in three cases was on the right side and in one on the left. The outgrowths varied somewhat in size; that sketched in Figure 5 being the largest seen. These foot-like outgrowths were pigmented a dark brown like the primary foot, but were without a ventral groove or anterior sucker. A single case was noted of a similar tiny outgrowth about midway along the length of the foot and distinctly on the lateral (right) edge. Pelseneer figures (Figure 94 bis, p. 133) a somewhat similar outgrowth on the right side of the foot of Cyclas cornea, which, however, was spheroidal.

An interesting case of foot abnormality was that sketched in Figure 6, where the accessory foot was ventral in position though slightly lateral, and the ventral groove of the main foot divided, the secondary foot in this instance being provided with a ventral groove. 


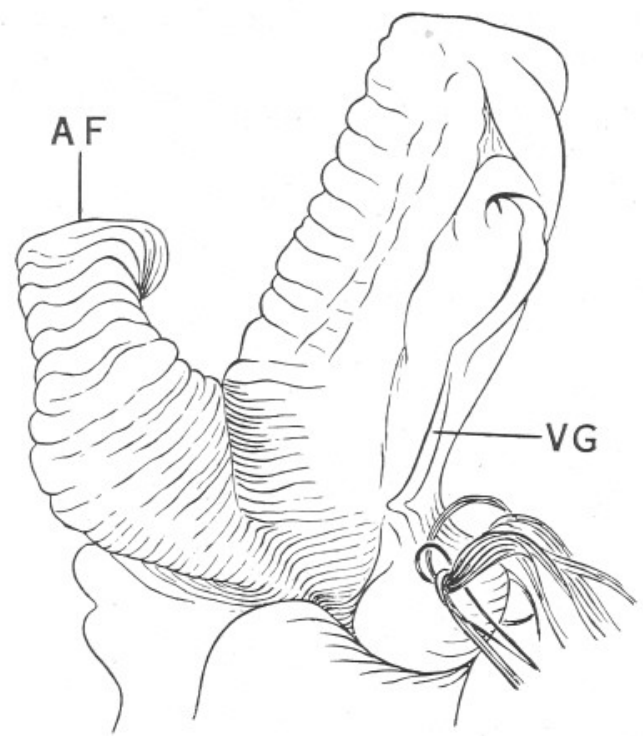

FIG. 5.-M. edulis. Foot with a small foot, AF, originating from near the base. VG, ventral groove of primary foot. $\times$ ca. $6 \frac{1}{4}$.

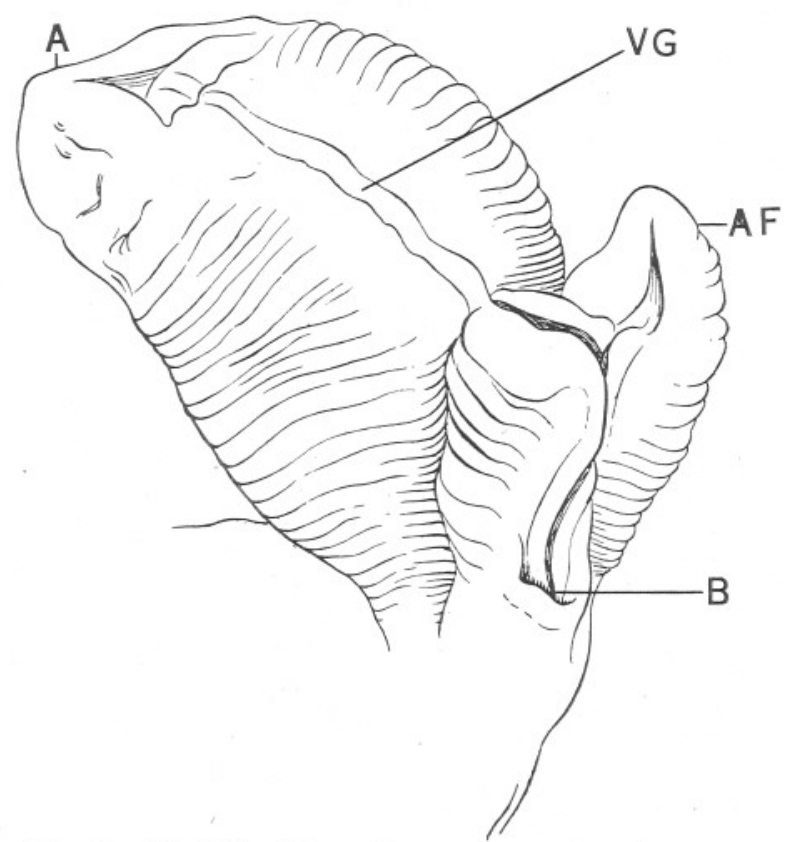

FIg. 6.-M. edulis. Foot with an accessory foot, AF, which is ventral in position and is provided with a ventral groove. $A$, tip, and VG, ventral groove of primary foot; $B$, byssus pit. $\times$ ca. $6 \frac{1}{4}$.

NEW SERLES.-VOL. XVII. NO. 2. JUNE, 1931. 
One Mytilus was noted in which the tip of the foot was missing, the foot being obviously injured and discoloured (Figure 7). There was a slight irregular outgrowth from the main foot anteriorly, but what is of especial interest was the presence of tiny foot-like protuberances, one on either side of, and seated on the anterior retractor muscles, that on the left being slightly more anterior in position than that on the right. These

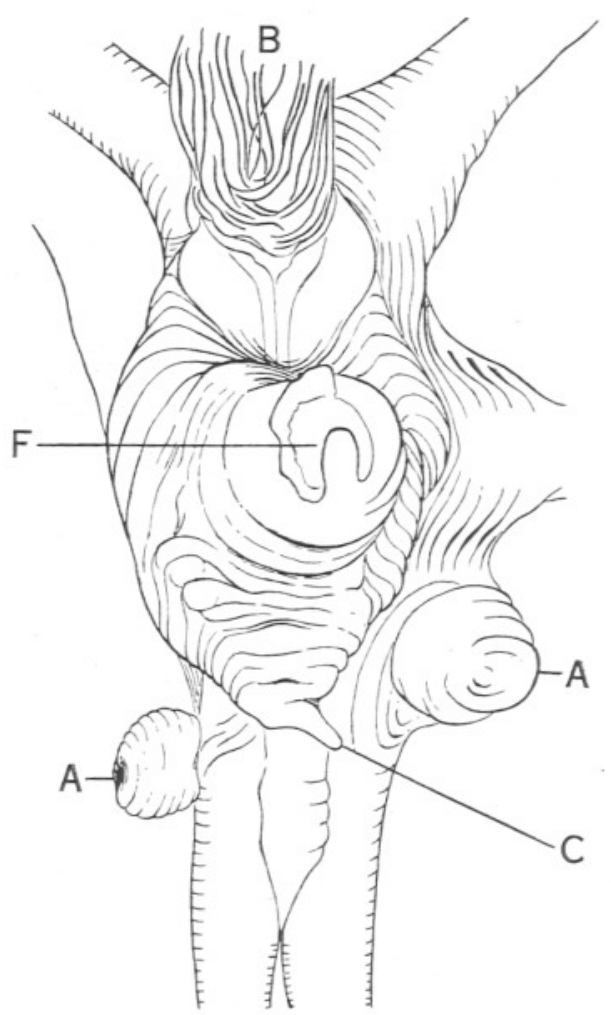

FrG. 7.-Sketch of foot of M. edulis, showing the tip missing as a result of injury, and two small foot-like outgrowths, $\mathrm{A}, \mathrm{A}$, one on either side of the anterior retractor muscles. $\mathrm{F}$, injured tip of primary foot; C, small outgrowth from primary foot; B, byssus. $\times$ ca. $6 \frac{1}{4}$.

were pigmented, but appeared to have no ventral groove. The figure shows them in a much contracted condition. As the foot is protruded from the shell in travelling, and during the spinning of the byssus, it is liable to suffer injury (see also Pelseneer, p. 133), as has evidently occurred in this specimen, but it is doubtful whether the foot-like outgrowths from near the base of the foot are due to this cause.

The position of the foot has been noticed to vary somewhat, in one instance being very anteriorly placed. 